\title{
Porque Formar Engenheiros Obsoletos - Um Caso de Estudo
}

\author{
Cesar da Costa \\ Instituto Federal de Educação Ciência e Tecnologia de São Paulo (IFSP) \\ Rua Pedro Vicente, 625 - 01109-010 - São Paulo - SP - Brasil \\ Departamento de Automação e Controle \\ ccostalifsp.edu.br
}

\begin{abstract}
Digital technology grows exponentially, new equipment and systems are specially designed to work in Industrial Automation. The areas linked to industrial automation have undergone major changes in recent years, whether technological changes or changes in the job market. This article aims, rather than proposing solutions, to provoke discussions about how and why to study automation nowadays (and how it is taught). Within this scenario, a new approach is necessary, in the sense of modernizing the teaching of Automation and Control in engineering courses.
\end{abstract}

Resumo. A tecnologia digital cresce de forma exponencial, novos equipamentos e sistemas são especialmente projetados para trabalhar em Automação Industrial. As áreas ligadas à automação industrial sofreram grandes mudanças nos últimos anos, sejam mudanças tecnológicas ou mudanças no mercado de trabalho. Este artigo visa, mais que propor soluções, provocar discussões sobre como e por que estudar automação hoje em dia (e como se ensina). Dentro desse cenário, uma nova abordagem faz-se necessária, no sentido de modernizar o ensino de Automação e Controle nos cursos de engenharia.

\section{Introdução}

Há algumas décadas mudança e inovação tem sido alvo de estudos de educadores e pesquisadores $[1,2,3]$. Destaca-se, também, os primeiros trabalhos relativos à inovação educacional, no Brasil. O termo inovação foi importado para educação do mundo da produção e da administração. $\mathrm{O}$ conceito de inovação relacionado à educação surgiu impregnado da concepção de que os avanços da Ciência e da Tecnologia determinariam o desenvolvimento econômico, social e cultural. Para esta visão o progresso científico e tecnológico deveria consistir em benefícios e valorização onde quer que fosse empregado seja no individuo, num produto ou no antigo processo.

A primeira revolução Industrial começou entre 1760 e 1840 na Inglaterra, com a substituição progressiva dos métodos artesanais por máquinas e ferramentas, pela exploração do carvão como energia alternativa à madeira e outros biocombustíveis, e pelo uso crescente da energia a vapor. As alterações dos processos produtivos tiveram consequências significativas a nível econômico e social [4].

Nas décadas que se seguiram e até o fim da segunda guerra mundial (1945), as evoluções foram significativas na área da indústria química, elétrica e do aço, assim 
como um aprimoramento significativo das técnicas existentes. Surgiram os primeiros barcos de aço movidos por potentes motores a vapor, revolucionando o transporte de mercadorias. Surgiram também as primeiras linhas de produção que viriam a permitir a produção em massa e a baixos custos. A invenção e inovação andaram de mãos dadas nesta que foi a segunda revolução Industrial.

Nas décadas de 1950 e 1970 começou-se a desenhar aquela que viria a ser considerada a terceira revolução Industrial, a revolução digital, com a proliferação e uso dos semicondutores, dos computadores, automação e robotização em linhas de produção, com informação armazenada e processada de forma digital, as comunicações, os telefones móveis e a internet.

No início do século XXI, com o desenvolvimento da Internet, sensores cada vez menores e potentes, com preços cada vez mais acessíveis, software e hardware cada vez mais sofisticado, criou-se gigantescas redes de "coisas" (IoT- Internet das Coisas), iniciou-se uma transformação na indústria, cujo impacto na competitividade, na sociedade e na economia será de tal forma, que irá transformar o mundo tal como o conhecemos [5]. Considerada a quarta revolução industrial surge a Industria 4.0.

\section{Visão da Industria 4.0}

A indústria 4.0 está fortemente focada na melhoria contínua em termos de eficiência, segurança, produtividade das operações e especialmente no retorno do investimento. São várias as tecnologias e tendências facilitadoras disponíveis. São consideradas como os principais pilares da indústria inteligente $[6,7]$ : internet das coisas e serviços (IoT e IoS); sistema Cyber-Physical e Big-Data.

\subsection{Internet das Coisas (IoT)}

O termo internet das Coisas "Internet of Things (IoT) refere-se a objetos físicos e virtuais ligados à internet, tem as suas raízes no MIT (Massachusetts Institute of Technology), quando em 1999 um grupo desenvolvia o seu trabalho na área da identificação por rádio frequência (RFID) conectada. Desde então, tem sido impulsionada pelo aparecimento e uso generalizado de sensores cada vez menores e baratos, assim como um avanço nos dispositivos móveis, comunicações wireless e tecnologias cloud.

\subsection{Sistemas Cyber-Physical (CPS)}

Cyber-Physical Systems (CPS) são sistemas que integram computação, redes de comunicação, computadores embutidos e processos físicos interagindo entre si e influenciando-se mutuamente. É o resultado da evolução tecnológica dos computadores, dos sensores, e das tecnologias de comunicação, que ao evoluírem no sentido de maior agilidade, capacidade de processamento e preços cada vez mais acessíveis tem permitido a sua conjugação de forma efetiva e em tempo real.

\subsection{Big Data}

O termo Big-Data refere-se a grandes quantidades de dados, que são armazenados a cada instante, resultante da existência de milhões de sistemas atualmente ligados à rede (IoT), produzindo dados em tempo real. 


\section{Por que Estudar Eletrônica}

Sempre que ocorre uma grande mudança na tecnologia, há um período durante o qual as instituições de ensino têm de decidir como e quando mudar a maneira de ensinar os assuntos. Nos últimos 20 anos, a tecnologia de sistemas digitais se moveu na direção da Lógica Programável. Apenas uma minoria das novas tecnologias de Automação Industrial recente usa circuitos digitais de pequena e média escala de integração na implementação de qualquer função de controle. A maioria dos circuitos digitais modernos está contida em um único dispositivo programável, FPGA (Field Programável Gate Array) ou CPLD (Complex Programmable Logic Devices).

Agora dois exemplos na área de eletrônica. Primeiro exemplo, é quase certeza encontrar na disciplina de eletrônica digital o tema Mapa de Karnaugh. Admite-se, é uma forma muito boa de simplificar circuitos combinacionais complexos, mas sua utilidade prática é nula. Quem simplifica circuitos combinacionais hoje? Qual o objetivo de tentar reduzir o número de portas lógicas? Quem faz projetos utilizando portas lógicas discretas? Segundo exemplo, em eletrônica analógica, muita gente defenderia que amplificador é um tema fundamental. Basta olhar as ementas da maioria dos cursos, estarão lá a junção BJT, PNP e NPN, as várias formas de polarização de transistor, as classes de amplificador. $\mathrm{Na}$ verdade, nada disso é fundamento, é apenas a implementações de uma tecnologia (diga-se de passagem, ultrapassada). Quem, nos dias atuais, monta um amplificador para fins práticos, polarizando transistores discretos? Por que se dedica tanto tempo a esse assunto, então? Esses dois exemplos propositalmente atacam dois temas que são, em geral, considerados fundamentos. É necessária uma reflexão sobre todo o conteúdo do curso de automação para identificar o que de fato é conceito fundamental útil para o futuro profissional e o que é tecnologia dos anos 70 .

\subsection{Foco da Formação}

Em termos de desenvolvimento, cada vez menos se desenvolve e produz equipamentos eletrônicos no Brasil. Pode-se lamentar e discutir as causas, mas o fato é que a proporção dos técnicos e engenheiros que vão se dedicar a projeto de circuitos eletrônicos a fim de desenvolver hardware, é cada vez menor. O projeto de equipamentos eletrônicos por sua vez também mudou. O nível de integração dos componentes faz com que cada vez se desenvolva menos circuito efetivamente. Utilizase componentes flexíveis com alto grau de integração ou módulos prontos, que serão configurados e programados. O tempo dedicado à programação dos sistemas embarcados é, tipicamente, várias vezes o tempo de desenvolvimento de circuitos. $\mathrm{Na}$ última década é difícil pensar em um desenvolvimento de produto que não tenha utilizado microcontroladores, processadores ou outra forma de programação (incluindo FPGAs e CPLDs).

\section{Resultados e Discussões}

Os planos curriculares, a grosso modo, partem do que se considera importante na formação de um determinado profissional. Essa complexa matriz de conhecimento é quebrada em áreas, por sua vez quebradas em disciplinas, e as disciplinas finalmente organizadas por tópicos. Do mesmo jeitinho que Descartes nos ensinou em 1637. Na hora de executar esse plano curricular toma-se o caminho inverso: partindo do que consideramos fundamentos e se vai acrescentando ou somando conhecimento, como se 
subíssemos uma escada para chegar ao topo de um edifício, de onde o estudante quando formado tenha (espera-se) a visão do todo. A questão é que a escada é muito longa, isto é, a tecnologia usada no cotidiano (profissional ou não) está muito além daquilo considerado fundamento, dos primeiros degraus. Novas tecnologias surgem a cada momento, portanto o edifício não para de crescer, o que é agravado pela redução nas cargas horárias dos cursos. Em resumo, o estudante entra no curso e começa a subir um prédio de 10 andares, degrau por degrau, mas só tem tempo para subir até o $7^{\circ}$ e, quando lá chega, o prédio já está com 15 andares.

\section{Conclusões}

A tecnologia muda rapidamente e afeta a vida das pessoas. Quando essa tecnologia está ligada à profissão, a responsabilidade de proporcionar um aprendizado significativo é muito grande. Não é fácil manter os currículos atualizados com essa velocidade de mudança, porém, de tempos em tempos, é necessário tomar decisões que alterem a estrutura dos currículos e permitam a professores e alunos assimilarem as mudanças tecnológicas ocorridas e, principalmente, estar mais bem preparados para o futuro. A eletrônica sofreu grandes mudanças na última década, em especial no que se refere ao mercado de trabalho no Brasil. As faculdades de engenharia e escolas técnicas que não conseguirem incorporar essas mudanças aos seus currículos correm o risco de entregar ao mercado um profissional que, recém-formado, já está obsoleto.

\section{Referências}

Fullan, M. (2002) "Los nuevos significados del cambio em la educación”. Barcelona: Octaedro.

Hernandez, F., Sancho, J. M. (2000) “Aprendendo com as inovações nas escolas”. Porto Alegre:Artmed.

Gomez, G. O. (2007) "Podemos ser mais criativos ao adotar a inovação tecnológica em educação? Uma proposta em comunicação”. Revista Matrizes. No 1, p.209-216.

Zarte, M., Pechmann, A., Wermann, J., Gosewehr, F., Colombo, A. W. (2016)” Building an Industry 4.0 - compliant lab environment to demonstrate connectivity between shop floor and TI levels of an enterprise”. Industrial Electronics Society. IECON 2016, 42 ${ }^{\text {nd }}$ Annual Conference of the IEEE, p. 23-26.

Baygin, M., Yetis, H., Karakose, M., Akin, E. (2016) "An effect analysis of industry 4.0 to higher education". $15^{\text {th }}$ International Conference on Information Technology Based Higher Education and Training (ITHET), p. 1- 4.

Huba, M., Kozak, S. (2016) “From e-learning to industry 4.0”. International Conference on Emerging eLearning Technologies and Applications (ICETA).

Schwab K. (2016) “The Fourth Industrial Revolution”. $1^{\text {st }}$ Edition, World Economic Forum. Crown Business: New York. ISBN; 9781524758869. 